\title{
Tissue Factor Expression Does Not Predict Mortality in Breast Cancer Patients
}

\author{
SIMON F. STÄMPFLI ${ }^{1,2^{*}}$, ALEXANDER AKHMEDOV $^{1 *}$, SILKE HAUSLADEN $^{3}$, \\ ZSUZSANNA VARGA ${ }^{3}$, KONSTANTIN J. DEDES $^{4}$, JENS HELLERMANN ${ }^{5}$, THOMAS F. LÜSCHER ${ }^{1,2}$, \\ GLEN KRISTIANSEN $^{6}$, FELIX C. TANNER ${ }^{1,2}$ and ALEXANDER BREITENSTEIN ${ }^{1,2}$ \\ ${ }^{I}$ Center for Molecular Cardiology, University of Zurich, Schlieren, Switzerland; \\ ${ }^{2}$ Department of Cardiology, University Heart Center Zurich, Zurich, Switzerland; \\ ${ }^{3}$ Institute of Pathology, University Hospital Zurich, Zurich, Switzerland; \\ ${ }^{4}$ Department of Gynecology, University Hospital Zurich, Zurich, Switzerland; \\ ${ }^{5}$ Department of Internal Medicine, Hospital Schiers, Schiers, Switzerland; \\ ${ }^{6}$ Institute of Pathology, University of Bonn, Bonn, Germany
}

\begin{abstract}
Background: Tissue factor (TF), the trigger of coagulation, not only initiates thrombus formation, but also elicits tumor growth and invasion in breast cancer. However, the characterization of TF expression in breast cancer tissue and its prognostic value remain unclear. Materials and Methods: Three hundred and three primary breast cancer specimens from the local tumor tissue database were immunostained for TF expression and evaluated semiquantitatively. Tumor characteristics ( size, grade, nodal status, and ER expression) as well as patient's survival were assessed. Results: Expression of TF was detected in 99\% of specimens with higher expression in invasive lobular than ductal carcinoma ( $p=0.008)$. TF expression correlated with ER expression $(p<0.0001)$ and inversely with tumor grade $(p=0.006)$. Survival analysis did not reveal any prognostic impact of TF expression ( $p=0.966)$. Conclusion: This study - by analyzing TF expression in the largest cohort of breast cancer patients so far - does not support a prognostic impact of TF expression.
\end{abstract}

Breast cancer is the most common malignant tumor among women in the Western civilization (1). It is commonly treated using specific therapeutic regimens depending on

*These Authors contributed equally to this study.

Correspondence to: Alexander Breitenstein, MD, Department of Cardiology, University Heart Center Zurich, Raemistrasse 100, CH8091 Zurich, Switzerland. Tel: +41 442551515, Fax: +41 442551616,e-mail: alexander.breitenstein@usz.ch

Key Words: Tissue factor, breast cancer, survival, hormone receptors, thrombosis, metastasis. cancer stage as well as histological and molecular characterization of the tumor tissue. Established prognostic markers in breast cancer include age, nodal status, tumor grade and size as well as estrogen receptors (ER) and HER2 status (2). However, estimation of prognosis still remains difficult (3) and some breast cancer types still lack specific therapeutic molecular targets. Therefore, it is important to identify additional tissue markers to improve patient surveillance and treatment.

Malignancies are often associated with a hypercoagulable state, and the overall risk for thrombotic events is significantly higher in cancer patients than in healthy individuals (4). Tissue factor (TF) is a 263-residue transmembrane glycoprotein acting as the key trigger of coagulation (5). By formation of a bimolecular complex with factor VII, coagulation is initiated leading to thrombin generation and ultimately thrombus formation (6). Under physiological conditions, TF is constitutively expressed in vascular smooth muscle cells and adventitial fibroblasts, allowing for rapid initiation of coagulation after vascular injury, while only very low levels of TF are present in the bloodstream (5).

In addition to its fundamental role in coagulation, as a transmembrane receptor TF regulates intracellular signaling cascades responsible for several biological processes such as tissue growth and angiogenesis (7-9). Experimental studies link TF expression with progression and invasiveness of malignancies by enhancing tumor growth, metastasis, and thrombosis (10-12). However, studies investigating the role of TF expression in breast cancer patients revealed inconsistent results, particularly regarding its prognostic significance (13-19). Therefore, this study aims at analyzing TF expression in biopsy specimens and determining its prognostic value in a large cohort of breast cancer patients. 


\section{Materials and Methods}

Patients and tissue samples. All samples of patients with primary invasive breast cancer from the tissue database at the Institute of Surgical Pathology, University Hospital Zurich, were used for this study. Follow-up was assessed by telephone interviews and patient files. Appropriate review board consent was obtained to allow the use of these materials and data for research purposes.

Tumor staging, grading and estrogen receptor status. Tumor characteristics including tumor size and grade, lymph node involvement, and ER expression were extracted from the clinical charts. In more detail, tumor histology was determined according to the International Agency for Research on Cancer (IARC) criteria (20), whereas staging of the disease followed TNM staging criteria (21). Tumors were graded according to Elston and Ellis (22).

Tissue factor immunohistochemistry. Tissue sections were processed as described (23). Briefly, formalin fixed and paraffin embedded tissue sections were mounted on tissue microarray slides, dewaxed with xylene, and gradually hydrated. The primary TF antibody (clone 1D10, American Diagnostica, Stamford, CT) was diluted at 1:1,000, incubated at room temperature for $1 \mathrm{~h}$, and detected using a peroxidase-labeled secondary antibody.

Evaluation of TF Immunohistochemical staining. Immunohistochemical TF stainings were independently examined by two clinical pathologists $(\mathrm{SH}, \mathrm{GK})$ who were blinded for patient characteristics and outcome. Intensity of TF was semiquantitatively scored as negative (0), weakly $(1+)$, moderately $(2+)$, or strongly $(3+)$ positive.

Statistical analysis. Statistical analysis was performed using Fisher's exact and $\chi^{2}$ tests to evaluate a correlation between TF expression pattern and clinicopathological values. Univariate survival analysis was done by the Kaplan-Meier method, and differences in survival curves assessed by the log rank test. A $p$-value $<0.05$ was regarded as significant.

\section{Results}

Patient characteristics and follow-up. Three hundred and three patients with primary breast cancer were included in the study. Age at the time of diagnosis ranged from 26 to 98 years with a median of 61 years. The average observation time for survival was 5.75 years. Follow-up data was available in 278 patients (92\%). Clinically and statistically significant minimal sample size was 273 .

Tumor characteristics. Detailed pathological characteristics are summarized in Table I. Invasive ductal carcinoma was described in 241 patients $(79.5 \%)$, whereas 44 patients $(14.5 \%)$ exhibited invasive lobular carcinoma. Two hundred and seven patients $(68.3 \%)$ revealed an ER-positive status. The majority of patients exhibited a tumor stage pT2 (132 patients, $43.6 \%) ; 103$ patients (34\%) had a stage pT1.

TF immunostaining in breast cancer tissues. Representative images of $\mathrm{TF}$ expression in breast cancer specimens are
Table I. Histo-pathological tumor characteristics.

\begin{tabular}{|c|c|}
\hline Variable & $\mathrm{n}(\%)$ \\
\hline Patients & $303(100 \%)$ \\
\hline \multicolumn{2}{|l|}{ Histology } \\
\hline Invasive ductal & $241(79.5 \%)$ \\
\hline Invasive lobular & $44(14.5 \%)$ \\
\hline Others & $11(3.6 \%)$ \\
\hline Unknown & $7(2.3 \%)$ \\
\hline \multicolumn{2}{|l|}{ Tumor size } \\
\hline pT1 & $103(34.0 \%)$ \\
\hline pT2 & $132(43.6 \%)$ \\
\hline pT3 & $16(5.3 \%)$ \\
\hline pT4 & $45(14.9 \%)$ \\
\hline Unknown & $7(2.3 \%)$ \\
\hline \multicolumn{2}{|l|}{ Tumor grade } \\
\hline G1 & $53(17.5 \%)$ \\
\hline G2 & $144(47.5 \%)$ \\
\hline G3 & $95(31.4 \%)$ \\
\hline Unknown & $11(3.6 \%)$ \\
\hline \multicolumn{2}{|l|}{ Lymph node stage } \\
\hline pNO & $103(34 \%)$ \\
\hline $\mathrm{pN} 1$ & $123(40.6 \%)$ \\
\hline $\mathrm{pN} 2$ & $15(5.0 \%)$ \\
\hline $\mathrm{pN} 3$ & $9(3.0 \%)$ \\
\hline Unknown & $53(17.5 \%)$ \\
\hline \multicolumn{2}{|l|}{ Estrogen receptor } \\
\hline Negative & $47(15.5 \%)$ \\
\hline Positive & $207(68.3 \%)$ \\
\hline Unknown & $49(16.2 \%)$ \\
\hline
\end{tabular}

shown in Figure 1; the data on cellular TF expression is summarized in Figure 2. TF was expressed in $99 \%$ of breast cancer specimens. 67 patients $(22.1 \%)$ exhibited weak $(1+)$, 186 patients $(61.4 \%)$ moderate $(2+)$, and 47 patients $(15.5 \%)$ strong (3+) positive TF staining.

Correlation of TF expression with tumor characteristics. A detailed overview on TF staining in respect of pathological and clinical parameters is shown in Table II. TF staining intensity correlated significantly with tumor histology $(\mathrm{n}=285 ; p=0.008)$ with higher values in invasive lobular carcinoma. TF correlated inversely with the tumor grade $(\mathrm{n}=292 ; p=0.006)$. Patients with a positive ER status exhibited higher TF expression $(n=254, p<0.0001)$. In contrast, no significant correlation was observed for tumor size $(\mathrm{n}=296, p=0.165)$ and lymph node status $(\mathrm{n}=250$, $p=0.981)$.

Survival analysis. The impact of different variables on overall survival was analyzed; an overview of the data is provided in Table III. The conventional prognostic markers like tumor size $(\mathrm{n}=271, p<0.0001)$, tumor grade $(\mathrm{n}=269$, $p=0.004)$, and ER expression $(\mathrm{n}=233, p=0.024)$ correlated 
Table II. Correlation of TF expression with tumor characteristics.

\begin{tabular}{|c|c|c|c|c|c|c|}
\hline Characteristic & Number & TF 0 & TF $1+$ & TF $2+$ & TF $3+$ & $p$-Value \\
\hline \multicolumn{7}{|l|}{ Histological type } \\
\hline Invasive ductal & 241 & $2(0.8 \%)$ & $54(22.4 \%)$ & $155(64.3 \%)$ & $30(12.4 \%)$ & 0.008 \\
\hline Invasive lobular & 44 & $0(0 \%)$ & $7(15.9 \%)$ & $24(54.5 \%)$ & $13(29.5 \%)$ & \\
\hline \multicolumn{7}{|l|}{ Tumor size } \\
\hline pT1 & 103 & $1(1 \%)$ & $16(15.5 \%)$ & $64(62.1 \%)$ & $22(21.4 \%)$ & 0.165 \\
\hline pT2 & 132 & $2(1.5 \%)$ & $34(25.8 \%)$ & $83(62.9 \%)$ & $13(9.8 \%)$ & \\
\hline $\mathrm{pT} 3 / 4$ & 61 & $0(0 \%)$ & $15(24.6 \%)$ & $36(59.0 \%)$ & $10(16.4 \%)$ & \\
\hline \multicolumn{7}{|l|}{ Tumor grade } \\
\hline G1 & 53 & $0(0 \%)$ & $10(18.9 \%)$ & $29(54.7 \%)$ & $14(26.4 \%)$ & 0.006 \\
\hline G2 & 144 & $1(0.7 \%)$ & $28(19.4 \%)$ & $90(62.5 \%)$ & $25(17.4 \%)$ & \\
\hline G3 & 95 & $2(2.1 \%)$ & $28(29.5 \%)$ & $61(64.2 \%)$ & $4(4.2 \%)$ & \\
\hline \multicolumn{7}{|l|}{ Lymph node status } \\
\hline pNO & 103 & $1(1 \%)$ & $23(22.3 \%)$ & $65(63.1 \%)$ & $14(13.6 \%)$ & 0.981 \\
\hline $\mathrm{pN} 1+$ & 147 & $2(1.4 \%)$ & $32(21.8 \%)$ & $91(61.9 \%)$ & $22(15.0 \%)$ & \\
\hline \multicolumn{7}{|l|}{ Estrogen receptor } \\
\hline Negative & 47 & $2(4.3 \%)$ & $19(40.4 \%)$ & $26(55.3 \%)$ & $0(0 \%)$ & $<0.0001$ \\
\hline Positive & 207 & $0(0 \%)$ & $31(15.0 \%)$ & $136(65.7 \%)$ & $40(19.3 \%)$ & \\
\hline
\end{tabular}

significantly with overall survival. Nodal status did not reach statistical significance $(\mathrm{n}=229, p=0.064)$.

The level of TF expression did not correlate with overall survival $(n=278, p=0.966)$. A Kaplan-Meier curve for different levels of TF expression is visualized in Figure 3.

\section{Discussion}

With 303 patients included and an average follow-up of nearly 6 years, the present study represents the largest and most comprehensive immunohistochemical analysis of TF expression in patients with breast cancer to date. The main findings were first that TF was highly expressed in the examined samples, which is in line with previous studies, reporting high TF expression in breast cancer $(13,14,18)$ and various other types of human cancer, especially in tumors of the lung, colon, and pancreas $(13,17,24-28)$. Second, TF was more expressed in lobular compared to ductal carcinoma, which has not been described so far. Third, consistent with a previous study (13), tumor size was not associated with expression of TF. In contrast, TF expression correlated with ER status with higher expression in ER positive subjects, while the above mentioned study observed no correlation (13). Fourth, TF expression correlated with the histologic grading of the carcinoma with higher expression in welldifferentiated tumors as compared to less differentiated ones. This unexpected finding is in contrast to findings in human pancreatic cancer (26) and glioma (29). Interestingly, in breast cancer tissue a correlation of TF expression and tumor grading has not been reported. This finding may suggest that highly-proliferating breast cancer cells exhibit a decreased
Table III. Overall survival and its correlation with tumor characteristics.

\begin{tabular}{lccc}
\hline Characteristic & Number of cases & Number of deaths & $p$-Value \\
\hline TF expression & 3 & 2 & 0.966 \\
0 & 60 & 21 & \\
1 & 171 & 47 & \\
2 & 44 & 11 & \\
3 & & & $<0.0001$ \\
Tumor size & 94 & 13 & \\
pT1 & 118 & 34 & \\
pT2 & 59 & 30 & 0.004 \\
pT3/4 & & & \\
Tumor grade & 48 & 6 & \\
G1 & 134 & 34 & \\
G2 & 87 & 37 & \\
G3 & & & \\
Lymph node status & 94 & 17 & \\
pN0 & 135 & 39 & \\
pN1+ & & & \\
Estrogen receptor & 43 & 18 & \\
$\quad$ Negative & 190 & 64 & \\
Positive & & & \\
\hline
\end{tabular}

ability to produce functional TF protein. Finally and surprisingly, TF expression was not associated with survival in this large cohort with a long follow-up.

As in previous reports, survival analysis revealed a correlation of mortality with tumor size (30) and grade (31). Similarly, ER status was predictive of outcome in this study population, while its prognostic value in the literature is inconsistent $(32,33)$. Lymph node metastasis did only show 

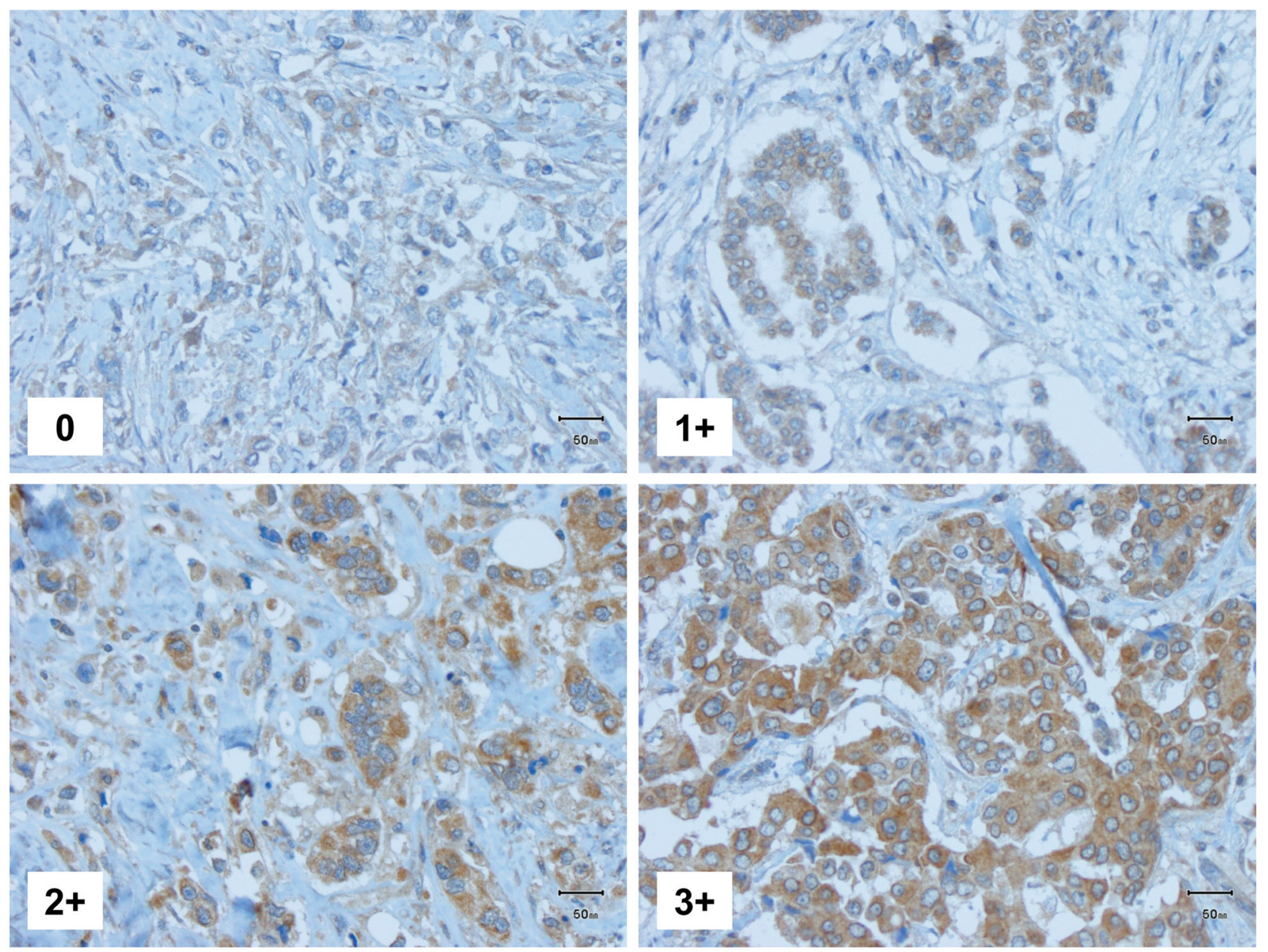

Figure 1. TF expression in breast cancer tissue. Representative tissue specimen without (0), weak (1+), moderate (2+), and high TF expression (3+).

a trend with a higher mortality rate, consistent with another study analyzing a comparable sample size (13), while in larger populations a correlation was observed (30).

The fact that TF was not predictive of survival was a surprising finding. Indeed, our results are in contrast to another publication (13) where a predictive role of TF was suggested in multivariate analysis. However, for survival analysis in the mentioned study patients without TF expression were compared to patients exhibiting TF expression irrespective of the quantity; and the number of patients - particularly in the non-TF group - was low. In addition, immunohistochemical protocols for TF detection have not been standardized. Moreover, detection of the extracellular domain of TF may be challenging and does not only depend on the antibody used, but also on the tissue preparation, the immunohistochemistry conditions, and the criteria defined to describe TF expression levels. For immunohistochemical analysis, mouse anti-human TF antibody clone 1D10 was used in this study, as it produces reproducible results in formalin-fixed breast cancer specimens (16). A semi-quantitative scoring system for TF expression was applied in accordance to a previous report (16). In the above mentioned study, a different anti-human TF antibody clone (HTF-K108) and a different scoring system were used (13) and TF staining signal was relatively weak. However, whether this methodological issues or the number of samples may account for the discrepancies of the results remains speculative. Interestingly, in the mentioned study expression of tumor $\mathrm{TF}$ was neither associated with disease-free survival nor any clinicopathological parameters like tumor size, hormone receptor status, lymph node status, venous invasion and metastasis (13).

Of note, the present study represents the largest analysis on TF and breast cancer so far. Regarding the higher number of patients included than in previous studies, it provides robust and novel information on the topic. TF did neither predict survival nor correlate with tumor size. The lack of 


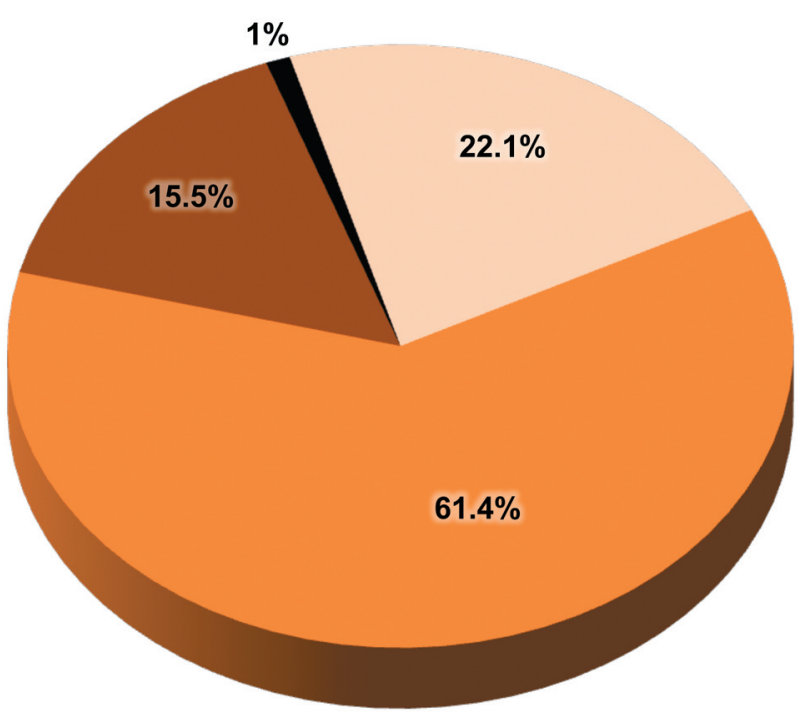

Tissue factor expression

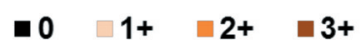

Figure 2. Distribution of cytoplasmic TF expression in breast cancer tissues.

impact on survival is particularly interesting since various experimental studies suggested that tumor cell derived TF may play a role in malignancy by modulating tumor growth, metastasis, and angiogenesis $(8,34-36)$. In a mouse model of pulmonary metastasis, TF inhibition by anti-TF antibodies or TF pathway inhibitor application even reduced the onset of metastasis $(28,37)$. In the present study, the observed decease of TF expression in heavily dedifferentiated cells may explain the lack of prognostic power.

In summary, this study - assessing the role of TF in the largest cohort of breast cancer patients so far - underscores that TF is highly expressed in this type of malignancy, but does neither predict survival nor correlate with tumor size. Thus, TF should not be used as a prognostic marker in breast cancer patients.

\section{Acknowledgements}

The Authors would like to thank Daniel P. Stiehl, Institute of Physiology, University Hospital Zurich, for his contribution to this project.

\section{References}

1 Jemal A, Siegel R, Xu J and Ward E: Cancer statistics. CA Cancer J Clin 60: 277-300, 2010.

2 Mori I, Yang Q and Kakudo K: Predictive and prognostic markers for invasive breast cancer. Pathol Int 52: 186-194, 2002.

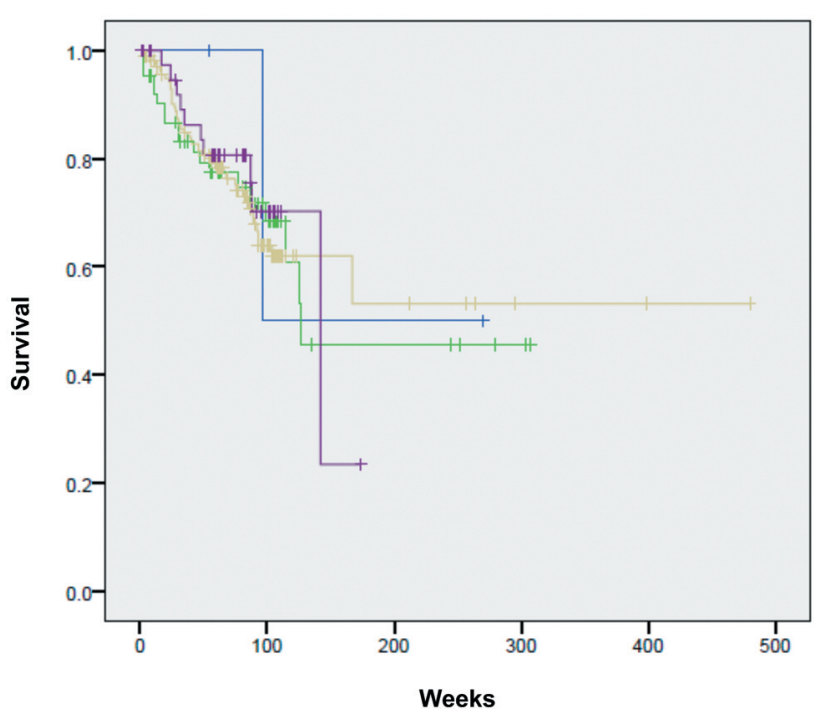

Tissue factor expression

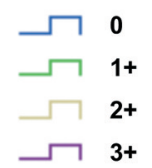

Figure 3. Univariate survival analysis (Kaplan-Meier) of TF expression in breast cancer. Overall survival times of all patients with breast cancer according to clinic-pathological factors and TF expression. TF expression level does not influence overall-survival in breast cancer patients.

3 Foulkes WD, Smith IE and Reis-Filho JS: Triple-negative breast cancer. N Engl J Med 363: 1938-1948, 2010.

4 Blom JW, Doggen CJ, Osanto S and Rosendaal FR: Malignancies, prothrombotic mutations, and the risk of venous thrombosis. Jama 293: 715-722, 2005.

5 Breitenstein A, Tanner FC and Luscher TF: Tissue factor and cardiovascular disease: Quo vadis? Circ J 74: 3-12, 2010.

6 Breitenstein A, Camici GG and Tanner FC: Tissue factor: Beyond coagulation in the cardiovascular system. Clin Sci (Lond) 118: 159-172, 2009.

7 Ruf W: Tissue factor and par signaling in tumor progression. Thromb Res 120(Suppl 2): S7-12, 2007.

8 Kasthuri RS, Taubman MB and Mackman N: Role of tissue factor in cancer. J Clin Oncol 27: 4834-4838, 2009.

9 Versteeg $\mathrm{HH}$ and Ruf W: Emerging insights in tissue factordependent signaling events. Semin Thromb Hemost 32: 24-32, 2006.

10 Shaker H, Harrison H, Clarke R, Landberg G, Bundred NJ, Versteeg $\mathrm{HH}$ and Kirwan CC: Tissue factor promotes breast cancer stem cell activity in vitro. Oncotarget 8: 25915-25927, 2017.

11 Kocaturk B, Tieken C, Vreeken D, Unlu B, Engels CC, de Kruijf EM, Kuppen PJ, Reitsma PH, Bogdanov VY and Versteeg HH: Alternatively spliced tissue factor synergizes with the estrogen receptor pathway in promoting breast cancer progression. J Thromb Haemost 13: 1683-1693, 2015. 
12 Rickles FR and Brenner B: Tissue factor and cancer. Semin Thromb Hemost 34: 143-145, 2008.

13 Ueno T, Toi M, Koike M, Nakamura S and Tominaga T: Tissue factor expression in breast cancer tissues: Its correlation with prognosis and plasma concentration. Br J Cancer 83: 164-170, 2000.

14 Vrana JA, Stang MT, Grande JP and Getz MJ: Expression of tissue factor in tumor stroma correlates with progression to invasive human breast cancer: Paracrine regulation by carcinoma cell-derived members of the transforming growth factor beta family. Cancer Res 56: 5063-5070, 1996.

15 Sturm U, Luther T, Albrecht S, Flossel C, Grossmann H and Muller M: Immunohistological detection of tissue factor in normal and abnormal human mammary glands using monoclonal antibodies. Virchows Arch A Pathol Anat Histopathol 421: 7986, 1992.

16 Ryden L, Grabau D, Schaffner F, Jonsson PE, Ruf W and Belting M: Evidence for tissue factor phosphorylation and its correlation with protease-activated receptor expression and the prognosis of primary breast cancer. Int J Cancer 126: 2330-2340, 2009.

17 Contrino J, Hair G, Kreutzer DL and Rickles FR: In situ detection of tissue factor in vascular endothelial cells: Correlation with the malignant phenotype of human breast disease. Nat Med 2: 209-215, 1996.

18 Wojtukiewicz MZ, Hempel D, Kruszewska J, Zimnoch L, Kisiel $\mathrm{W}$ and Sierko E: Erythropoietin receptor and tissue factor are coexpressed in human breast cancer cells. J BUON 20: 1426$1431,2015$.

19 Wojtukiewicz MZ, Sierko E, Skalij P, Kaminska M, Zimnoch L, Brekken RA and Thorpe PE: Granulocyte-colony stimulating factor receptor, tissue factor, and vegf-r bound vegf in human breast cancer in loco. Adv Clin Exp Med 25: 505-511, 2016.

20 Bocker W: Who classification of breast tumors and tumors of the female genital organs: Pathology and genetics. Verh Dtsch Ges Pathol 86: 116-119, 2002.

21 Wittekind C, Compton CC, Greene FL and Sobin LH: Tnm residual tumor classification revisited. Cancer 94: 2511-2516, 2002.

22 Elston EW and Ellis IO: Method for grading breast cancer. J Clin Pathol 46: 189-190, 1993.

23 Kristiansen G, Rose M, Geisler C, Fritzsche FR, Gerhardt J, Luke C, Ladhoff AM, Knuchel R, Dietel M, Moch H, Varga Z, Theurillat JP, Gorr TA and Dahl E: Endogenous myoglobin in human breast cancer is a hallmark of luminal cancer phenotype. Br J Cancer 102: 1736-1745, 2010.

24 Wojtukiewicz MZ, Sierko E, Klement P and Rak J: The hemostatic system and angiogenesis in malignancy. Neoplasia 3: 371-384, 2001.

25 Sawada M, Miyake S, Ohdama S, Matsubara O, Masuda S, Yakumaru $\mathrm{K}$ and Yoshizawa $\mathrm{Y}$ : Expression of tissue factor in non-small-cell lung cancers and its relationship to metastasis. $\mathrm{Br}$ J Cancer 79: 472-477, 1999.
26 Kakkar AK, Lemoine NR, Scully MF, Tebbutt S and Williamson $\mathrm{RC}$ : Tissue factor expression correlates with histological grade in human pancreatic cancer. Br J Surg 82: 1101-1104, 1995.

27 Rickles FR, Patierno S and Fernandez PM: Tissue factor, thrombin, and cancer. Chest 124: 58S-68S, 2003.

28 Mueller BM, Reisfeld RA, Edgington TS and Ruf W: Expression of tissue factor by melanoma cells promotes efficient hematogenous metastasis. Proc Natl Acad Sci USA 89: 1183211836, 1992.

29 Hamada K, Kuratsu J, Saitoh Y, Takeshima H, Nishi T and Ushio Y: Expression of tissue factor correlates with grade of malignancy in human glioma. Cancer 77: 1877-1883, 1996.

30 Carter CL, Allen C and Henson DE: Relation of tumor size, lymph node status, and survival in 24,740 breast cancer cases. Cancer 63: 181-187, 1989.

31 Elston CW and Ellis IO: Pathological prognostic factors in breast cancer. I. The value of histological grade in breast cancer: Experience from a large study with long-term follow-up. Histopathology 19: 403-410, 1991.

32 Pichon MF, Pallud C, Brunet M and Milgrom E: Relationship of presence of progesterone receptors to prognosis in early breast cancer. Cancer Res 40: 3357-3360, 1980.

33 Winstanley J, Cooke T, George WD, Murray G, Holt S, Croton R, Griffiths K and Nicholson R: The long term prognostic significance of oestrogen receptor analysis in early carcinoma of the breast. Br J Cancer 64: 99-101, 1991.

34 Albrektsen T, Sorensen BB, Hjorto GM, Fleckner J, Rao LV and Petersen LC: Transcriptional program induced by factor viiatissue factor, par1 and par2 in mda-mb-231 cells. J Thromb Haemost 5: 1588-1597, 2007.

35 Liu Y and Mueller BM: Protease-activated receptor-2 regulates vascular endothelial growth factor expression in mda-mb-231 cells via mapk pathways. Biochem Biophys Res Commun 344: 1263-1270, 2006.

36 Hjortoe GM, Petersen LC, Albrektsen T, Sorensen BB, Norby PL, Mandal SK, Pendurthi UR and Rao LV: Tissue factor-factor viia-specific up-regulation of il-8 expression in mda-mb-231 cells is mediated by par- 2 and results in increased cell migration. Blood 103: 3029-3037, 2004.

37 Amirkhosravi A, Meyer T, Chang JY, Amaya M, Siddiqui F, Desai $\mathrm{H}$ and Francis JL: Tissue factor pathway inhibitor reduces experimental lung metastasis of b16 melanoma. Thromb Haemost 87: 930-936, 2002. 